\title{
The effects of irrigation solution temperature on modified triple antibiotic paste removal from root canals using XP-Endo Finisher
}

\author{
Yahya Güven, ${ }^{1}$ (i) Ahmet Demirhan Uygun' ${ }^{1}$ \\ Department of Endodontics, Afyonkarahisar Health Sciences University Faculty of Dentistry, Afyonkarahisar, Turkey
}

Purpose: This study aimed to study the effects of irrigation solution temperature on the removal of intracanal medicament from root canals using XP-Endo Finisher (XPF).

Methods: This study used 72 extracted, single-root maxillary central human teeth prepared with an R40 Reciproc file, and the roots were separated into two parts lengthwise. In the apical and coronal regions, two grooves of $3 \mathrm{~mm}$ length were opened. Afterward, modified triple antibiotic paste (mTAP) was placed inside these canals and the roots were joined. Then, they were randomly divided into 6 groups: Group 1: conventional syringe irrigation $(\mathrm{CSI})$ and $21{ }^{\circ} \mathrm{C}$ sodium hypochlorite $(\mathrm{NaOCl})$, Group 2: XPF and $21^{\circ} \mathrm{C} \mathrm{NaOCl}$, Group 3: $\mathrm{CSI}$ and $37^{\circ} \mathrm{C} \mathrm{NaOCl}$, Group 4: XPF and $37^{\circ} \mathrm{C} \mathrm{NaOCl}$, Group 5: $\mathrm{CSI}$ and $50^{\circ} \mathrm{C} \mathrm{NaOCl}$, Group 6: XPF and $50^{\circ} \mathrm{C} \mathrm{NaOCl}$.

Results: A significant difference was observed in the apical region $(p<0.05)$. Groups 2,4 , and 6 showed significantly better results in removing mTAP than Groups 1 and $3(p<0.05)$.

Conclusion: It has been observed that using $\mathrm{NaOCl}$ solution at different temperatures does not affect the efficiency of XPF in removing mTAP. However, the solution increased the effectiveness of the CSI technique.

Keywords: Apical groove, conventional syringe irrigation, modified triple antibiotic paste, temperature, XP-Endo Finisher.

\section{Introduction}

The triple antibiotic paste (TAP), which is obtained by mixing equal ratios of metronidazole, ciprofloxacin, and minocycline, was developed in 1996 by Hoshino et al. (1). TAP has been frequently used as an intracanal medicament with successful clinical outcomes (2). Previous studies reported the effectiveness of TAP in disinfection of immature teeth with apical periodontitis (3). However, there are various concerns related to the complete remov- al of the medicament from the root canal system $(4,5)$. A potential concern about using intracanal medicament is that it may lead to bacterial resistance. Additionally, using intracanal minocycline may lead to tooth coloration and potential aesthetical complications (6). Therefore, minocycline was removed from TAP due to its color-changing effect (7). Clindamycin was added instead, and this combination has been used as the modified triple antibiotic paste (mTAP) (8).

Cite this article as: Güven Y, Uygun AD. The effects of irrigation solution temperature on modified triple antibiotic paste removal from root canals using XP-endo Finisher. Turk Endod J 2021;6:39-44.

Correspondence: Yahya Güven. Department of Endodontics, Afyonkarahisar Healht Sciences

University Faculty of Dentistry, Afyonkarahisar, Turkey.

Tel: +90 272 - 2167900 e-mail: yahyaguven52@outlook.com

Submitted: May 03, 2021 Accepted: May 31, 2021

(O2021 Turkish Endodontic Society 
Intracanal medicaments should be removed completely from root canals to achieve success in endodontic treatment (9). Conventional syringe irrigation (CSI) is considered one of the most prevalently used methods for cleaning root canals. However, some studies have revealed that this technique is ineffective in intracanal medicament removal (10).

The XP-Endo Finisher (XPF) (FKG Dentaire SA, La Chaux-de-Fonds, Switzerland) is a nontapered file with a small core, size 25 , based on nickel-titanium (NiTi) alloy shape memory principles. This finisher was developed for use after any root canal preparation of size $\geq 25$ to reach irregular areas and sections that are difficult to access and remove intracanal medications (8).

In the literature, there are many studies related to TAP removal from root canals $(4,5)$. However, to the best of our knowledge, studies on the effects of irrigation solution temperature on mTAP removal from root canals are limited. Thus, this study aims to investigate the effectiveness of irrigation solution temperature and the XPF in removing mTAP from root canals. The null hypothesis is that the irrigation solution temperature does not affect the mTAP removal capacity of the XPF (1) and the CSI technique (2).

\section{Materials and Methods}

This study was approved by the Ethics Committee of the Faculty of Medicine, Afyonkarahisar Health Sciences University (2021-70).

\section{Tooth Selection}

The inclusion criteria included the following: must have completed its development, must have no previous root canal treatment, and root tip must have closed. The exclusion criteria included the following: root surface caries, excessively wide oval canal, and fracture on the root surface.

Seventy-two single-root, single-canal maxillary central human teeth satisfying these criteria were used. The collected teeth were kept in physiological saline solution until use. Ultrasonic devices were used to remove the soft tissue and hard tissue residues around the extracted teeth. To confirm that the teeth were single-canal teeth, radiographs were obtained.

\section{Specimen Preparation}

To obtain standard root lengths and working lengths, the crown of each tooth was removed at the cementoenamel junction using diamond burs operating under cold water cooling. Access to pulp chambers was provided by adjust- ing the root lengths to $17 \pm 0.5 \mathrm{~mm}$. Apical patency was checked using a \#10 K-file (DiaDent, Chongju, Korea). The coronal access was prepared with a Gates-Glidden \#3 bur. After determining the working lengths of the teeth to be $1 \mathrm{~mm}$ short of the apical region with a \#20 K-file (DiaDent, Chongju, Korea), root canal preparation was completed with an R40 Reciproc (VDW, Munich, Germany) file and a Silver Reciproc (VDW, Munich, Germany) endodontic motor in the "RECIPROC ALL" mode. During the preparation procedures, $2 \mathrm{~mL}$ of $2.5 \%$ sodium hypochlorite $(\mathrm{NaOCl})$ was used. The prepared specimens were put into Eppendorf tubes (Eppendorf-Elkay, Shrewsbury, MA, USA) filled with a silicone measurement substance (Zetaplus Soft, Zhermack Clinical, Badia Polesine, Italy). Then, the specimens were taken out of the tubes, and longitudinal grooves were prepared on their buccal and lingual root surfaces with a diamond tip disk under water cooling. This process was performed with care not to damage the canal walls. The roots were separated into two halves using a spatula. In the apical and coronal regions, two standard grooves were prepared with a length of $3 \mathrm{~mm}$, width of $0.2 \mathrm{~mm}$, and depth of $0.5 \mathrm{~mm}$ (Fig. 1). The distances of the grooves from the apical region were 2-5 $\mathrm{mm}$ and 11-14 mm, respectively. The debris on the groove and root surface was cleaned using a brush. The final irrigation process of the surfaces was performed using $5 \mathrm{~mL}$ of $2.5 \%$ and $5 \mathrm{~mL}$ of $17 \%$ EDTA. Then, paper points were used to dry the canals.

\section{mTAP Application}

Equal amounts of metronidazole (IE Ulagay, Istanbul, Turkey), clindamycin (Bilim Ilaç, Istanbul, Turkey), and ciprofloxacin (Bayer Türk Kimya, Istanbul, Turkey) were mixed with distilled water (3:1 powder/liquid ratio). The grooves were filled with the prepared mTAP, and the halves of the roots were joined and carefully placed into Eppendorf vials. The coronal access was closed with a temporary filling material (Cavit 3M ESPE), and the specimens were kept for 1 week in $100 \%$ humid environment

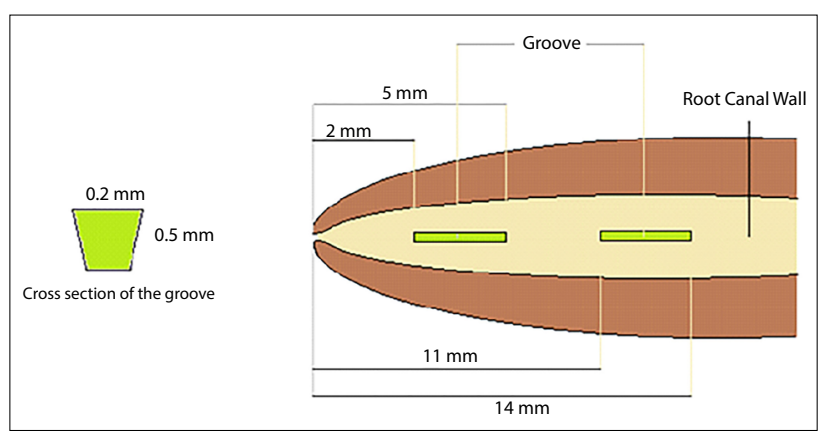

Fig. 1. Schematic representation of the location and size of the artificial standardized grooves. 
at $37^{\circ} \mathrm{C}$. Based on the irrigation protocols, the specimens were randomly divided into 6 groups (12 per group).

Group 1: $10 \mathrm{~mL}, 21{ }^{\circ} \mathrm{C}$, and $2.5 \% \mathrm{NaOCl}$ was administered to the canal $1 \mathrm{~mm}$ short of the apical region using a 30-G (NaviTip) syringe.

Group 2: The canal was irrigated using $5 \mathrm{~mL}, 21{ }^{\circ} \mathrm{C}$, and $2.5 \% \mathrm{NaOCl}$ and a $30-\mathrm{G}$ (NaviTip) syringe. Afterward, $\mathrm{XPF}$ was placed into the canal $1 \mathrm{~mm}$ short of the working lengths and moved up and down inside the canal at a width of $5 \mathrm{~mm}$. The solution was activated for $1 \mathrm{~min}$, with $800 \mathrm{rpm} 1 \mathrm{Ncm}$ torque, according to the manufacturer's instructions. The final irrigation procedure was performed using $5 \mathrm{~mL}, 21{ }^{\circ} \mathrm{C}$, and $2.5 \% \mathrm{NaOCl}$.

Group 3: The irrigation protocol was the same as that in Group 1, but the solution used was $10 \mathrm{~mL}, 37^{\circ} \mathrm{C}$, and $2.5 \% \mathrm{NaOCl}$.

Group 4: The canal was irrigated using $5 \mathrm{~mL}, 37^{\circ} \mathrm{C}$, and $2.5 \% \mathrm{NaOCl}$ and a $30-\mathrm{G}$ (NaviTip) syringe. The XPF protocol was the same as that in Group 2. The final irrigation procedure was performed using $5 \mathrm{~mL}, 37{ }^{\circ} \mathrm{C}$, and $2.5 \%$ $\mathrm{NaOCl}$.

Group 5: The irrigation protocol was the same as that in Group 1 , but the solution used was $10 \mathrm{~mL}, 50{ }^{\circ} \mathrm{C}$, and $2.5 \% \mathrm{NaOCl}$.

Group 6: The canal was irrigated using $5 \mathrm{~mL}, 50{ }^{\circ} \mathrm{C}$, and $2.5 \% \mathrm{NaOCl}$ and a $30-\mathrm{G}$ (NaviTip) syringe. The XPF protocol was the same as that in Group 2. The final irrigation procedure was performed with $5 \mathrm{~mL}, 50{ }^{\circ} \mathrm{C}$, and $2.5 \%$ $\mathrm{NaOCl}$.

All irrigation protocols were applied at body temperature. Both solutions and irrigation syringes were warmed so that the solution temperature did not decrease during the procedure, and the solutions were given at a flow rate of $0.20 \mathrm{~mL} / \mathrm{s}-1$. After the irrigation process was completed, the canals were dried using paper points, and the roots were separated to examine the mTAP remaining in the grooves. Images obtained with a stereomicroscope at a $20 \times$ magnification rate were transferred to a computer with the help of a digital camera. The images were coded so that two researchers would be blind to the groups. The quantity of mTAP remaining in the grooves was assessed by an endodontist with twice calibration according to the assessment scale used by van der Sluis et al. (11).

The scoring process was as follows: score 0: empty groove, score 1: mTAP present in less than half of the groove, score 2: mTAP present in more than half but not the entirety of the groove, and score 3: groove completely filled with mTAP (Fig. 2).

\section{Statistical Analysis}

A total of 60 random images were assessed again 1 week later to test the interrater reliability, and the results were analyzed using the Kappa test. The statistical analyses were conducted by the Kruskal-Wallis and Mann-Whitney U tests using the Bonferroni correction. The tests were conducted in a confidence interval of $95 \%(\mathrm{p}=0.05)$. Data analysis was performed using SPSS software (SPSS Inc., Chicago, IL, USA).

\section{Results}

There was a good level of agreement between the two researchers (Kappa statistic $=0.977)$. The interrater reliability was $96 \%$ for the first researcher and $94 \%$ for the second researcher.

Table 1 shows the distribution of the scores based on the root areas. When the effectiveness of the irrigation techniques in removing mTAP was examined based on intergroup comparisons, there was no statistically significant
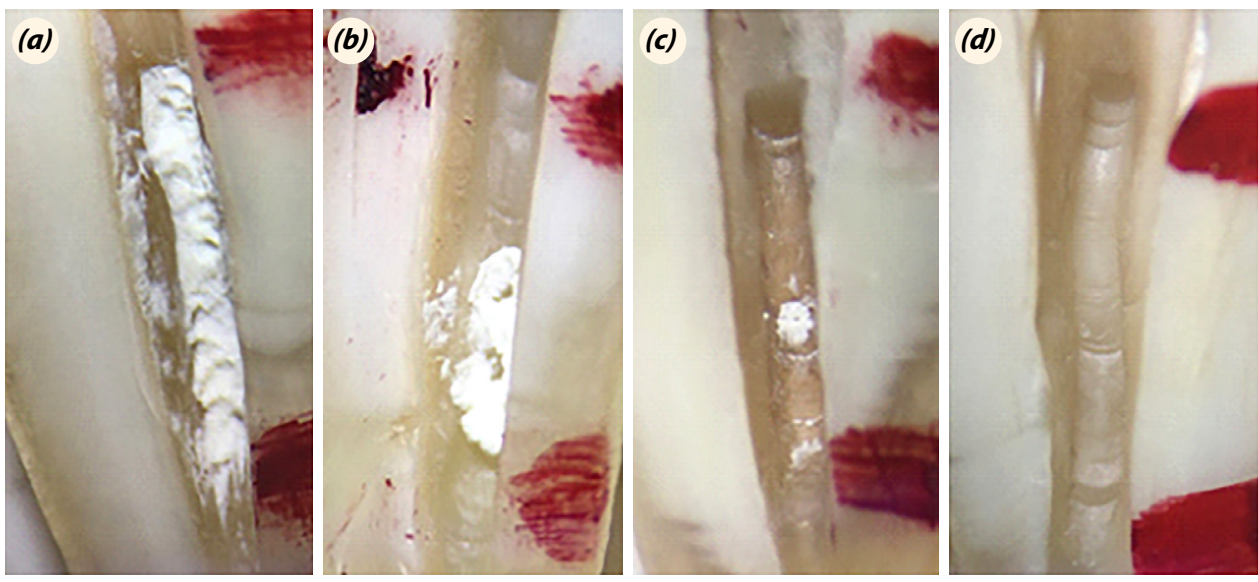

Fig. 2. Stereomicroscope images representing the scores. (a) Score 3: groove is completely filled with modified triple antibiotic paste (mTAP). (b) Score 2: groove has more than half of mTAP but not completely full. (c) Score 1: groove has less than half of MTAP. (d) Score 0: the groove is empty. 
Table 1. Distribution of modified triple antibiotic paste removal scores by root regions (median [interquartile range])

\begin{tabular}{|c|c|c|c|c|c|}
\hline & Group & Median & Interquartilerange & Minimum & Maximum \\
\hline \multirow[t]{6}{*}{ Coronal } & Group 1 & $2.00^{\text {A.a }}$ & 0.75 & 1.00 & 3.00 \\
\hline & Group 2 & $2.00^{\text {A.a }}$ & 0.75 & 0.00 & 3.00 \\
\hline & Group 3 & $2.00^{\text {A.a }}$ & 0.00 & 1.00 & 3.00 \\
\hline & Group 4 & $1.50^{\text {A.a }}$ & 1.00 & 0.00 & 3.00 \\
\hline & Group 5 & $2.00^{\text {A.a }}$ & 1.75 & 0.00 & 3.00 \\
\hline & Group 6 & $2.00^{\text {A.a }}$ & 1.75 & 0.00 & 2.00 \\
\hline \multirow[t]{6}{*}{ Apical } & Group 1 & $2.50^{\text {A.a }}$ & 1.00 & 1.00 & 3.00 \\
\hline & Group 2 & $1.00^{\text {B.b }}$ & 0.75 & 0.00 & 2.00 \\
\hline & Group 3 & $2.00^{\text {A.a }}$ & 1.75 & 0.00 & 3.00 \\
\hline & Group 4 & $0.50^{B . b}$ & 1.00 & 0.00 & 2.00 \\
\hline & Group 5 & $1.00^{\text {B.a }}$ & 0.00 & 1.00 & 2.00 \\
\hline & Group 6 & $1.00^{B . b}$ & 1.00 & 0.00 & 2.00 \\
\hline
\end{tabular}

Capital letters in the same column indicate a significant difference between groups and lower case letters indicate a significant difference within the group ( $\mathrm{p}<0.05$ ).

difference among the groups in the coronal third $(\mathrm{p}>$ $0.05)$. In the apical region, mTAP was more effectively removed in Group 5 than in Group 1 and in Groups 2, 4, and 6 than in Groups 1 and $3(\mathrm{p}<0.05)$. In the intragroup comparisons, there was significantly less mTAP in the apical region than in the coronal region in all XPF groups $(\mathrm{p}<0.05)$. There was no significant difference in the CSI groups in terms of the coronal and apical mTAP removal scores $(\mathrm{p}>0.05)$.

\section{Discussion}

In the literature, there are studies that have used different techniques and solutions for removing mTAP from root canals $(4,8)$. However, to the best of our knowledge, there is limited information on the effects of irrigation solution temperature on the procedure of mTAP removal from the root canal. According to Göktürk et al. (12), increasing the temperature of $\mathrm{NaOCl}$ did not create a statistically significant difference in the capacity of XPF to remove calcium hydroxide in the apical region. In line with their study, the present study found that although increasing the temperature of the $\mathrm{NaOCl}$ solution did not play a significant role in the effectiveness of XPF in removing $\mathrm{mTAP}$, it positively affected the effectiveness of the CSI technique for mTAP removal. The occurrence of this situation is related to the fact that the heated solution reaches the irregularities in the root canal better. The high irrigation solution temperature had a positive effect on the scores of the groups, but there was a statistically significant difference only in the CSI group. Therefore, the null hypothesis that the solution temperature would create no difference between different irrigation techniques in terms of removal of mTAP from root canals was partially rejected. Nevertheless, since there are no other studies in the literature that examined the use of XPF to remove mTAP with a $\mathrm{NaOCl}$ solution at different temperatures, our results may not be directly compared to those of other studies.

Previous studies found the XPF to be superior to CSI in terms of intracanal medicament removal $(10,13)$. However, Donnermeyer et al. (13) did not find a difference between the XPF and CSI techniques in terms of medicament removal from grooves in the coronal region. This was in line with the findings of our study. Regarding the double antibiotic paste removal from artificial irregularities in the coronal, middle, and apical regions of root canals, Göktürk et al. (14) determined that XPF was superior to the CSI technique in the coronal and middle regions, whereas both methods had a similar effect in the apical region.

In this study, less mTAP was observed in the apical grooves than in the coronal grooves in all XPF groups. This situation may be associated with the fact that the last $10 \mathrm{~mm}$ tip part of the file takes a spoon shape while working in the canal; thus, it increases its cleaning effectiveness by contacting the dentin surface (8). Türkaydın et al. (15) investigated the effectiveness of XPF, PUI, and CSI techniques in removing TAP from the root canal. Their study results revealed that the XPF provided better results than other techniques. This situation may be explained by the fact that the XPF contracts and expands based on the root canal anatomy; during its rotation movement within the canal, it accesses areas that are difficult to access with standard tools and cleans these areas.

The technique of separating roots into two parts used in our study is a prevalent technique that is used in the determination of residual substances inside canals $(4,5,12,13)$. In this technique, the grooves opened on the outer surfaces of the teeth must not reach the root canal, and there 
must be no contact with the residual substances in the canal while separating the roots. Furthermore, the root separation technique allows complete determination of the root canal borders and a three-dimensional examination (4). There are some limitations of our study. One of these limitations is that the grooves formed on the canal surface cannot fully imitate the irregularities in the root canals.

Increasing the temperature of $\mathrm{NaOCl}$ that is used in root canal treatment may be an alternative method to increase its effectiveness (16). Studies have determined that $\mathrm{NaOCl}$ dissolves tissues better when its temperature is increased $(17,18)$. Moreover, heated $\mathrm{NaOCl}$ solutions remove organic debris from dentinal shavings more effectively than their unheated form (19). In our study, increasing the temperature of the $\mathrm{NaOCl}$ solution created a statistically significant difference in mTAP removal from artificial grooves in the apical region for the CSI technique. The number of studies in the literature investigating the effects of irrigation solution temperature on mTAP removal from root canals is limited. Increasing the temperatures of different solutions and testing them in relation to this topic may be eye-opening.

\section{Conclusion}

While the irrigation solution temperature did not affect the capacity of the XPF in removing mTAP from the root canals, it increased the effectiveness of the CSI technique.

Authorship Contributions: Concept: Y.G.; Design: A.D.U.; Supervision: Y.G.; Materials: A.D.U.; Data: Y.G.; Analysis: A.D.U.; Literature search: A.D.U.; Writing: Y.G.; Critical revision: Y.G.

Source of Funding ॠ None declared.

Conflict of Interest: None declared.

Ethical Approval: The study protocol was approved by the Afyonkarahisar Health Sciences University Faculty of Medicine Clinical Research Ethics Commitee (date: 08.01.2021, protocol no: 2021-70).

Informed consent: Written informed consent was obtained from patients who participated in this study.

\section{References}

1. Hoshino E, Kurihara-Ando N, Sato I, et al. In-vitro antibacterial susceptibility of bacteria taken from infected root dentine to a mixture of ciprofloxacin, metronidazole and minocycline. Int Endod J 1996; 29: 125-30. [CrossRef]

2. Arslan H, Ahmed HMA, Şahin Y, et al. Regenerative endodontic procedures in necrotic mature teeth with periapical radiolucencies: a preliminary randomized clinical study.
J Endod 2019; 45: 863-72. [CrossRef]

3. Windley W 3rd, Teixeira F, Levin L, Sigurdsson A, Trope M. Disinfection of immature teeth with a triple antibiotic paste. J Endod 2005; 31: 439-43. [CrossRef]

4. Akman M, Akbulut MB, Aydinbelge HA, Belli S. Comparison of different irrigation activation regimens and conventional irrigation techniques for the removal of modified triple antibiotic paste from root canals. J Endod 2015; 41: 720-4. [CrossRef]

5. Arslan H, Capar ID, Saygili G, et al. Efficacy of various irrigation protocols on the removal of triple antibiotic paste. Int Endod J 2014; 47: 594-9. [CrossRef]

6. Parirokh M, Torabinejad M. Mineral trioxide aggregate: a comprehensive literature review-Part I* chemical, physical, and antibacterial properties. J Endod 2010; 36: 16-27.

7. Trope M. Treatment of the immature tooth with a nonvital pulp and apical periodontitis. Dent Clin North Am 2010; 54: 313-24. [CrossRef]

8. Sağlam BC, Hazar E, Koçak S, Koçak MM. Efficacy of XP-Endo Finisher and passive ultrasonic irrigation on modified triple antibiotic paste removal. Cumhuriyet Dent J 2019; 22: 108-13. [CrossRef]

9. Zhu W, Zhu X, Huang GT, Cheung GS, Dissanayaka WL, Zhang C. Regeneration of dental pulp tissue in immature teeth with apical periodontitis using platelet-rich plasma and dental pulp cells. Int Endod J 2013; 46: 96270. [CrossRef]

10. Uygun AD, Gündoğdu EC, Arslan H, Ersoy İ. Efficacy of XP-Endo Finisher and TRUShape 3D conforming file compared to conventional and ultrasonic irrigation in removing calcium hydroxide. Aust Endod J 2017; 43: 89-93. [CrossRef]

11. van der Sluis LW, Wu MK, Wesselink PR. The evaluation of removal of calcium hydroxide paste from an artificial standardized groove in the apical root canal using different irrigation methodologies. Int Endod J 2007; 40: 52-7.

12. Göktürk H, Özkoçak İ, Büyükgebiz F. Effect of temperature on the ability of XP-Endo Finisher to remove calcium hydroxide from root canal irregularities: ex vivo. Acta Odontol Turc 2018; 35: 38-43. [CrossRef]

13. Donnermeyer D, Wyrsch H, Bürklein S, Schäfer E. Removal of calcium hydroxide from artificial grooves in straight root canals: sonic activation using EDDY versus passive ultrasonic 1rrigation and XPendo Finisher. J Endod 2019; 45: 322-6. [CrossRef]

14. Gokturk H, Ozkocak I, Buyukgebiz F, Demir O. An in vitro evaluation of various irrigation techniques for the removal of double antibiotic paste from root canal surfaces. J Appl Oral Sci 2016; 24: 568-74. [CrossRef]

15. Turkaydin D, Demir E, Basturk FB, Sazak Övecoglu H. Efficacy of XP-Endo Finisher in the removal of triple antibiotic paste from immature root canals. J Endod 2017; 43: 1528-31. [CrossRef] 
16. Zehnder M. Root canal irrigants. J Endod 2006; 32: 38998. [CrossRef]

17. Cunningham WT, Balekjian AY. Effect of temperature on collagen-dissolving ability of sodium hypochlorite endodontic irrigant. Oral Surg Oral Med Oral Pathol 1980; 49: $175-7$. [CrossRef]
18. The SD. The solvent action of sodium hypochlorite on fixed and unfixed necrotic tissue. Oral Surg Oral Med Oral Pathol 1979; 47: 558-61. [CrossRef]

19. Kamburis JJ, Barker TH, Barfield RD, Eleazer PD. Removal of organic debris from bovine dentin shavings. J En$\operatorname{dod} 2003 ; 29$ : 559-61. [CrossRef] 